\title{
Effects of Media Ratings on Children and Adolescents: A Litmus Test of the Forbidden Fruit Effect
}

\author{
Jordy F. Gosselt, Menno D. T. De Jong, \& Joris J. Van Hoof \\ Department of Communication Studies, Faculty of Behavioral Sciences, University of Twente, Enschede, \\ The Netherlands
}

\begin{abstract}
Media ratings serve to inform parents about and protect minors from violent or otherwise harmful media content. Most of these systems use age pictograms and content warning pictograms for entertainment products. An experiment was conducted to investigate whether these pictograms, contrary to their purpose, have an appealing effect on children and adolescents. Compared to prior studies into this "forbidden fruit effect" concerning $D V D s$ and games, more realistic materials were used. In the experiment, 322 elementary school students (9-11 years) and 335 high school students (13-15 years) were exposed to 10 DVD or game covers and asked to judge the products' attractiveness. The results show that the pictograms did not increase the attractiveness of games and DVDs for children and adolescents.
\end{abstract}

doi:10.1111/j.1460-2466.2011.01597.x

To protect children and adolescents from the risks associated with exposure to various products, most countries have introduced age restrictions for the sale of risky products like tobacco and alcohol. Media products can also be considered to be risky products, as movies, television programs and video games often contain potentially harmful elements. Selling these products to children who are too young is illegal in The Netherlands. However, mature movies, television programs, and games seem to be popular among children and adolescents (Buchman \& Funk, 1996; Nikken \& Jansz, 2007). Media rating systems aim to prevent potentially negative effects of harmful media on children and adolescents. Media ratings (also known as age classification systems, warning label systems, or restrictive ratings) are meant to provide minors, their parents or caregivers, and retailers with appropriate, reliable, and valid information concerning the content of media products and in that way serve as a tool restricting minors' access and exposure to potentially harmful media.

Corresponding author: Jordy F. Gosselt; e-mail: j.f.gosselt@utwente.nl 
Much has been said and published about the effects that detrimental media may have on the viewer, especially on violence and aggression. On the one side there is research that indicates that the effects are nonexistent or low (e.g., Ferguson \& Kilburn, 2010; Savage \& Yancey, 2008; Sherry, 2001, 2007). Other studies, however, did find a relationship between children's exposure to harmful (e.g., violent) media content and the development of undesirable attitudes and behaviors, violent behaviors in particular (e.g., Anderson \& Bushman, 2001; Bushman \& Anderson, 2001; Bushman \& Huesmann, 2001; Earles, Alexander, Johnson, Liverpool, \& McGhee, 2002; Hogben, 1998; Huesmann, 2007; Konijn, Nije Bijvank, \& Bushman, 2006; Paik \& Comstock, 1994).

Media ratings are used throughout the world, and many countries have their own rating systems with their own pictograms and their own regulations. In general, age pictograms show whether a media product's content is potentially harmful for minors below a given age (also known as evaluative ratings). In addition, the media product's actual content is often specified with warning pictograms (descriptive ratings). Both the age classification labels and the warning labels can be placed on covers, packaging, posters, and other advertising materials, and can be shown at the start of or during a movie, television program, or game. The goal of media rating systems is to provide individuals (especially parents and retailers) with appropriate information about media products so that they can make informed decisions regarding the media consumption of children and adolescents (Gentile, Humphrey, \& Walsh, 2005).

Although media rating systems are meant to protect children and adolescents from harmful content, several researchers also mention the possibility of an undesirable side effect: Age classifications and warning pictograms may make the potentially harmful media products more appealing to (young) viewers. This is known as the forbidden fruit effect, a reference to the Biblical story in which God forbids Adam and Eve to eat the fruit from the tree of knowledge. This effect is connected with psychological theories such as reactance theory and commodity theory. Reactance theory assumes that people like the freedom to behave according to their own wishes. When this freedom is threatened, they experience psychological reactance, an unpleasant emotional state that motivates them to restore the threatened or lost freedom (Brehm, 1972; Brehm \& Brehm, 1981; Bushman \& Stack, 1996). Simmons (1992) demonstrated this in a study in which a group of participants were informed that a particular music album (out of nine) was declared legally obscene in Great Britain. Compared to a control group, these participants ranked this particular album significantly higher on attractiveness. Commodity theory predicts that any commodity (in our case: a movie, television program, or game) that is perceived as unavailable (e.g., by means of age classifications for specific categories), that cannot be obtained, or that can be obtained only with much effort will be valued more than commodities that can be obtained freely (Bushman \& Stack, 1996).

Research, particularly in the United States, suggests that age classifications and warning pictograms may indeed have a forbidden fruit effect on children and adolescents (Bushman, 2006; Bushman \& Cantor, 2003; Bushman \& Stack, 1996). 
An overview by Bushman and Cantor (2003) shows that high age classifications and content warnings have a forbidden fruit effect on children and adolescents (from 8 to 17 years), who find such products more attractive. However, when children are younger than 8 years old, a so-called tainted fruit effect may occur: Too-high age classifications and content warnings decrease the attractiveness of media for them. In sum, the attractiveness decreased until the age of 8 , increased until about age 22, and then decreased. Differences were found for male and female participants: The average effect size among male participants was .25, whereas the average effect size among female participants was only .003. Bushman and Cantor included studies on television programs, movies, games, and music in their meta-analysis. They do not report significant differences between types of media products.

Various methods have been used to establish the occurrence of forbidden fruit effects. An early Belgian study compared audience size and viewers' appreciation of movies broadcast with and without sexual content advisories (Herman \& Leyens, 1977). Consumer surveys have been conducted in which adults were asked whether ratings would affect their own viewing behavior ("Television programs and movies sometimes have announcements that they contain mature subject matter. When you see such an announcement, are you more or less likely to watch the program?"; Ingold, 1999) or the choices that they made regarding their children's exposure to media productions (Wurtzel \& Surlin, 1978), or where children had to indicate which program they were most likely to watch (Sneegas \& Plank, 1998).

The strongest form of evidence, however, is based on experimental research designs. Several experimental studies have been designed to investigate the occurrence of a forbidden (or tainted) fruit effect (Austin, 1980; Bahk, 1998; Bushman, 2006; Bushman \& Stack, 1996; Cantor \& Harrison, 1997; Cantor, Harrison, \& Nathanson, 1998; Christenson, 1992; Nije Bijvank, Konijn, Bushman, \& Roelofsma, 2008; Simmons, 1992). Table 1 provides an overview of experimental studies that were incorporated in Bushman and Cantor's (2003) meta-analysis, supplemented with more recent studies on this topic. Special attention is paid to the experimental materials used.

As can be seen in Table 1, all recent experiments found a forbidden fruit effect associated with media rating systems. The practical relevance of most of these findings, however, is threatened by the characteristics of the experimental materials used. In general, the stimuli used concerning the characteristics of the media products were relatively poor (brief verbal descriptions of the products), whereas the stimuli concerning the age classifications and content warnings were often strongly emphasized (e.g., "the labels were printed in bold, uppercase font, and were enclosed in asterisks," Bushman, 2006; Bushman \& Stack, 1996; and "this is the only album declared legally obscene in Great Britain," Simmons, 1992). In the case of television booklets, the relatively brief descriptions of the television programs may be realistic. In the case of other media products, however, such materials do not correspond to real-life situations, in which people are confronted with rich illustrations on covers and product descriptions and considerably less prominent pictograms. Christenson (1992) did include actual music album covers and used normal-sized classification 


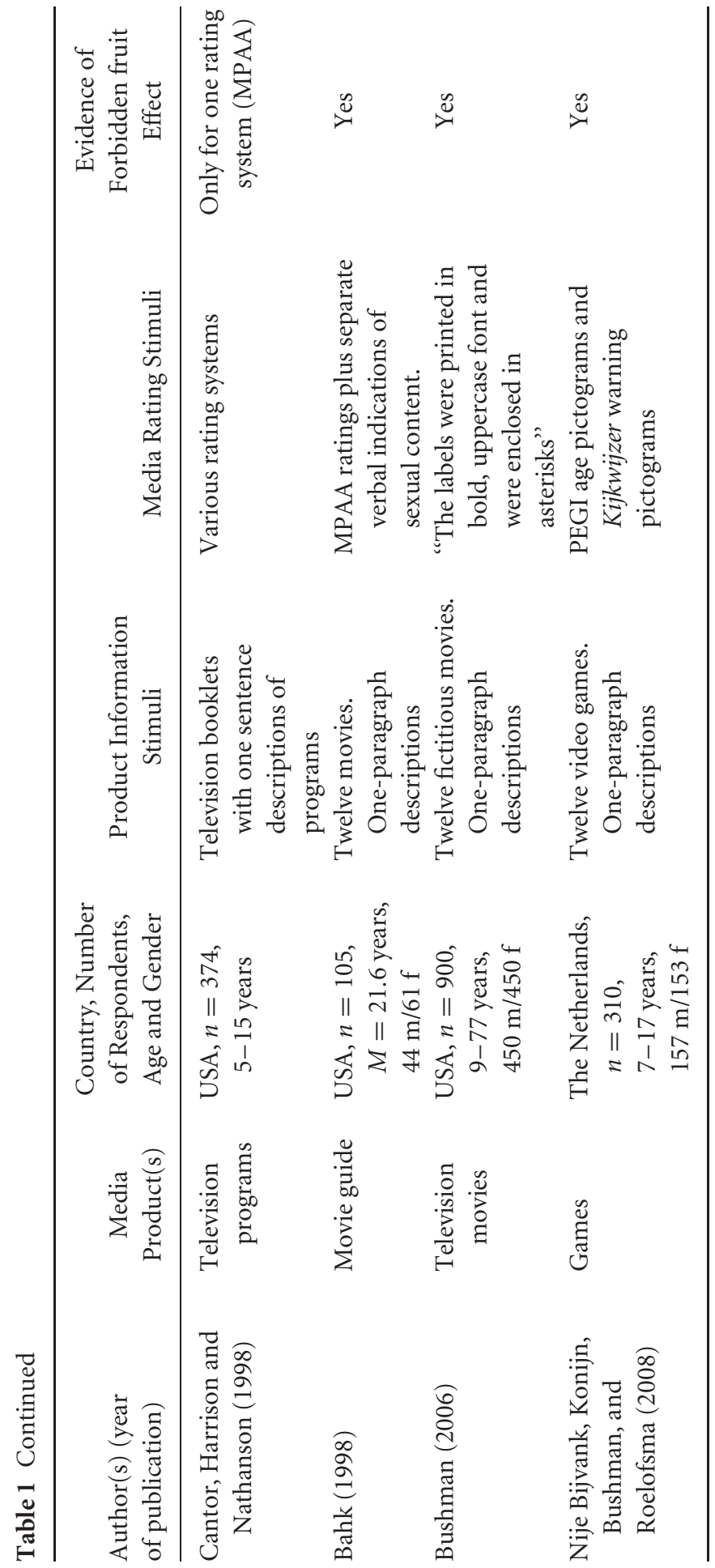


labels. Instead of the forbidden fruit effect, the "Parental Advisory-Explicit Lyrics" labels on the album covers caused a tainted fruit effect.

The results do not suggest that national contexts play an important role: The only divergence in results can be found among the American studies. The first experimental study by Austin (1980) did not find a forbidden fruit effect. The other study that did not find such an affect (Christenson, 1992) was the only one using realistic stimulus materials. The only experimental study about the forbidden fruit effect in The Netherlands reported that both age labels and violent content labels increased the attractiveness of videogames for children and adolescents (Nije Bijvank et al., 2008).

Christenson's (1992) study involved music albums. To further explore the occurrence of forbidden or tainted fruit effects in media products like DVDs and games, a more realistic research design is necessary than the ones used in previous studies involving such media products. The research described in this article involves complete DVD and game covers and actual age and warning pictograms. As such, it can be considered to be a litmus test for the forbidden fruit effect: Is it something that is likely to occur in daily life, or is it something that can only be found in artificial contexts with materials that do not resemble the media products children and adolescents encounter? On the basis of the earlier studies on the forbidden fruit effect and on the basis of the reactance theory and commodity theory, we hypothesize that age classifications and warning pictograms make potentially harmful media products more appealing to (young) viewers. Furthermore, we expect media ratings to have a stronger effect on older children than on younger children.

H1: Age classifications and warning pictograms make potentially harmful media products more appealing to (young) viewers.

H2: Media ratings have a stronger effect on older children than on younger children.

\section{Methods}

An experimental study was designed to investigate whether media rating pictograms make DVDs and games more appealing to children and adolescents. For this experiment, we used the age and warning pictograms that are commonly used in The Netherlands. Two systems were used: a Dutch media-rating system focusing on movies, television programs, and DVDs (called Kijkwijzer; cf. Valkenburg, Beentjes, Nikken \& Tan, 2002); and a European system specifically aimed at (video) games (called Pan European Game Information, PEGI).

\section{Context of the Dutch media rating systems}

In many European countries, different regulatory systems have been established for television, movies, DVDs/videos, and games. The regulations on games are based on harmonized self-regulation at the European level, while the other media products (DVDs, movies, and television programs) are controlled by combined governmental and nongovernmental regulatory activities at the national level. The background of 
European legislation is the United Nations Convention on the Rights of the Child and the EU Audiovisual Media Services Directive (2007/65/EC).

In 2001, Kijkwijzer was introduced. Kijkwijzer is a system of coregulation between the Dutch government and the Dutch entertainment industry. Two years later, the Interactive Software Federation of Europe (ISFE) introduced PEGI, a similar (European) system, specifically aimed at video games. This piece of self-regulation was based on national classification systems. Although representatives of the entertainment industry are, in principle, free to decide whether or not they want to join Kijkwijzer or PEGI, the decision not to do so may have adverse consequences in practice. For public broadcasters, however, using Kijkwijzer is compulsory under the Dutch Media Law. In both systems, classifications are assigned to media products by trained coders on the basis of scientifically developed criteria (Valkenburg et al., 2002). Kijkwijzer and PEGI are both maintained by the (Dutch) entertainment industry. PEGI and Kijkwijzer are the only two media rating systems in The Netherlands, which means that all Dutch games are rated using PEGI only, and all Dutch DVDs are rated using Kijkwijzer only.

\section{Design}

In a randomized independent groups experiment, 322 elementary school students and 335 high school students were exposed to 10 covers of DVDs or games. In a 4 (age pictogram: no age pictogram/all ages pictogram/12 years/16 years) $\times 2$ (warning pictograms: present/absent) $\times 2$ (age categories: $9-11 / 13-15) \times 2$ (media products: DVDs/games) design, participants were asked to judge the attractiveness of media products. To this end, they were shown the covers of existing DVDs or games in actual size on a laptop screen. Four of the covers were shown without any pictograms (and served as fillers). The remaining six covers formed the experimental material. Participants in both age categories were randomly assigned to either the DVD or game condition. They were then randomly assigned to one of the eight experimental groups. These eight groups were based on the presence or absence of an age pictogram (no age classification, "all ages," "12 years," and "16 years") and on the presence or absence of a combination of three warning pictograms (violence, sexuality, and abusive language). We used a combination of three warning labels to emphasize the mature content of the media products, to avoid the possible connotations of one specific warning label, and because of the prevalence and importance to children and parents of these three labels in the Dutch situation. Combinations of age labels and several warning labels are not uncommon in the Dutch situation. It is also possible that a DVD or game cover contains a label for "all ages" accompanied by warning pictograms. Table 2 shows the design for the DVD condition (using the Kijkwijzer pictograms) and game condition (using the European PEGI pictograms). As can be seen, somewhat different pictograms are used for DVDs and games in The Netherlands. Several studies show that the familiarity with and understanding of the pictograms among children and adolescents is generally high (NICAM, 2006; Nielsen Games, 2008; Van Grinsven, 2009). 
Table 2 Experimental Design

\begin{tabular}{|c|c|c|c|c|}
\hline Group & Age Pictogram & Warning Pictograms & $\begin{array}{l}\text { Participants } \\
9-11 \text { years }\end{array}$ & $\begin{array}{l}\text { Participants } \\
13-15 \text { years }\end{array}$ \\
\hline \multicolumn{5}{|c|}{ DVD condition } \\
\hline 1 & & - & 21 & 21 \\
\hline 2 & & & 18 & 22 \\
\hline 3 & & - & 21 & 21 \\
\hline 4 & & & 22 & 22 \\
\hline 5 & & - & 18 & 22 \\
\hline 6 & & & 20 & 20 \\
\hline 7 & - & - & 19 & 22 \\
\hline 8 & - & & 20 & 18 \\
\hline Total & & & 159 & 168 \\
\hline \multicolumn{5}{|c|}{ Game condition } \\
\hline 1 & 2 & - & 22 & 18 \\
\hline 2 & & 8 & 20 & 22 \\
\hline 3 & & - & 21 & 21 \\
\hline 4 & & ) & 21 & 21 \\
\hline 5 & & - & 20 & 23 \\
\hline 6 & & Q & 20 & 22 \\
\hline 7 & - & - & 19 & 20 \\
\hline 8 & - & S) & 20 & 20 \\
\hline Total & & & 163 & 167 \\
\hline
\end{tabular}

Experimental material: The DVDs and games

In the experiment, participants were exposed to the covers of existing DVDs and games on a computer screen. To reduce potential bias, the DVDs and games included had to meet three requirements. First, the DVDs and games had to be relatively unfamiliar to the participants. If participants were already familiar with a DVD or game, their judgments regarding the attractiveness would probably be based on their (previous) experiences, or on the recommendations of others. They might even remember the age classification and/or warning pictograms assigned to it. Second, 
the DVDs and games had to be realistically connected with a broad range of age classifications so that the manipulations were credible in all conditions in the eyes of the participants. Third, the covers of the DVDs and games had to be attractive to children and adolescents to a reasonable level.

To meet these three conditions, a preliminary study was conducted with 17 elementary school students (9-11 years) and 46 high school students ( $13-15$ years). The number of boys and girls in this study was almost equal. Participants in the preliminary study were exposed to the covers of 25 DVDs and 25 games (without age classifications and warning pictograms), followed by three questions: (a) Do you know this DVD/game? (yes/no), (b) For which age category would you estimate this DVD/game to be appropriate? (DVDs: all ages/6 years/12 years/16 years; games: all ages $/ 3+/ 7+/ 12+/ 16+/ 18+$ ), and (c) How eager are you to watch this DVD/ play this game? (on a 5-point scale ranging from "not eager at all" to "very eager"). The initial selection of 25 DVDs and 25 games was based on our own estimations of the unfamiliarity, the ambiguity of the age classifications, and the attractiveness of each product. Table 3 shows the characteristics of the 10 DVDs and 10 games that were eventually selected for the experiment.

As can be seen, all DVDs and games that were selected in the end were relatively unfamiliar and were not univocally connected with one particular age classification. Finally, the attractiveness scores of the DVDs and games were largely comparable.

The participants' unfamiliarity with the DVD and games included in the experiment was also verified afterwards using one question at the end of the experiment. Seventy-eight percent of the participants indicated that they did not know any of the DVDs or games they saw in the experiment. The remaining participants only mentioned one of the DVDs or games, which, in the majority of the cases, proved to be the ones that were used as fillers or the DVD or game that was used as an example at the start of the experiment. The 12 participants who indicated that they knew one or more of the experimental DVDs or games were removed from the sample. The pictograms were shown in a normal size and placed on the standard places on the covers of the DVDs and games (Figure 1).

\section{Research instrument}

After the cover of a DVD or game was shown, the respondents had to answer four questions on a 10-point scale: (a) How eager are you to watch this DVD/ play this game? (not eager at all, very eager), (b) How boring does this DVD/game seem to you? (not boring at all, very boring; this item was recoded in the analysis), (c) How nice does this DVD/game seem to you? (not nice at all, very nice), and (d) Which grade, ranging from 1 to 10 , would you give this DVD/game? For the entire sample these four questions proved to form reliable scales, with Cronbach's $\alpha$ varying from .88 to .90 .

In addition, data were collected concerning two possibly relevant personal characteristics of the participants: reactance and sensation seeking. Reactance is the tendency of participants to exhibit a rebellious attitude: Choosing a DVD or game 
Table 3 Scores of the Pretest on Suitability of the Experimental Material

\begin{tabular}{|c|c|c|c|c|}
\hline & $\begin{array}{l}\text { Percentage } \\
\text { unknown }\end{array}$ & $\begin{array}{l}\text { Number of different } \\
\text { age classifications }\end{array}$ & $\begin{array}{c}\text { Mean attractiveness } \\
\text { score }(S D)\end{array}$ & $\begin{array}{l}\text { Function in } \\
\text { experiment }\end{array}$ \\
\hline \multicolumn{5}{|c|}{ DVD } \\
\hline A & 98 & 4 & $1.98(1.25)$ & Experimental \\
\hline B & 92 & 4 & $2.24(1.19)$ & Experimental \\
\hline C & 91 & 4 & $2.44(1.39)$ & Experimental \\
\hline $\mathrm{D}$ & 91 & 4 & $1.92(1.17)$ & Experimental \\
\hline E & 92 & 4 & $2.10(1.38)$ & Experimental \\
\hline $\mathrm{F}$ & 91 & 4 & $2.39(1.31)$ & Experimental \\
\hline G & 86 & 4 & $2.27(1.34)$ & Filler \\
\hline $\mathrm{H}$ & 89 & 4 & $2.76(1.32)$ & Filler \\
\hline I & 87 & 4 & $2.87(1.63)$ & Filler \\
\hline$J$ & 89 & 4 & $2.10(1.32)$ & Filler \\
\hline \multicolumn{5}{|c|}{ Games } \\
\hline A & 89 & 5 & $1.58(1.03)$ & Experimental \\
\hline B & 91 & 5 & $2.13(1.36)$ & Experimental \\
\hline C & 87 & 3 & $1.95(1.11)$ & Experimental \\
\hline $\mathrm{D}$ & 91 & 5 & $1.76(1.17)$ & Experimental \\
\hline $\mathrm{E}$ & 91 & 6 & $2.02(1.31)$ & Experimental \\
\hline $\mathrm{F}$ & 86 & 6 & $1.57(1.13)$ & Experimental \\
\hline G & 84 & 6 & $1.73(1.15)$ & Filler \\
\hline $\mathrm{H}$ & 79 & 6 & $2.33(1.61)$ & Filler \\
\hline I & 84 & 6 & $2.05(1.29)$ & Filler \\
\hline J & 79 & 5 & $2.13(1.43)$ & Filler \\
\hline
\end{tabular}

Note: Attractiveness scores were measured on a 5-point scale (How eager are you to watch this $\mathrm{DVD} /$ play this game? $1=$ not eager at all; $5=$ very eager .

with a high age classification or with extreme contents may be an expression of this attitude. The questions concerning reactance were based on two existing scales (Hong \& Page, 1989; Konijn, Nije Bijvank, \& Bushman, 2007), but the formulation of the questions was geared to the young research population. Examples of the items are "I find it exciting to do things that I am not supposed to do" and "I feel angry when people tell me what to do". The questions had the form of 5-point Likert scales (strongly disagree, strongly agree). The scale consisted of eight items and had a Cronbach's $\alpha$ of .65. Sensation seeking concerns the preference of participants for tension, for example by choosing a DVD or game with a high age classification or warning pictograms. The questions concerning sensation seeking were based on the Brief Sensation Seeking Scale (Hoyle, Stephenson, Palmgreen, Lorch \& Donohew, 2002), complemented with two items from Konijn et al. (2007). Examples of the items used are "Sometimes I do exciting things, even if they are dangerous" and "I get restless when I stay home for too long." This scale consisted of 10 items and was reliable (Cronbach's $\alpha=.79$ ). 


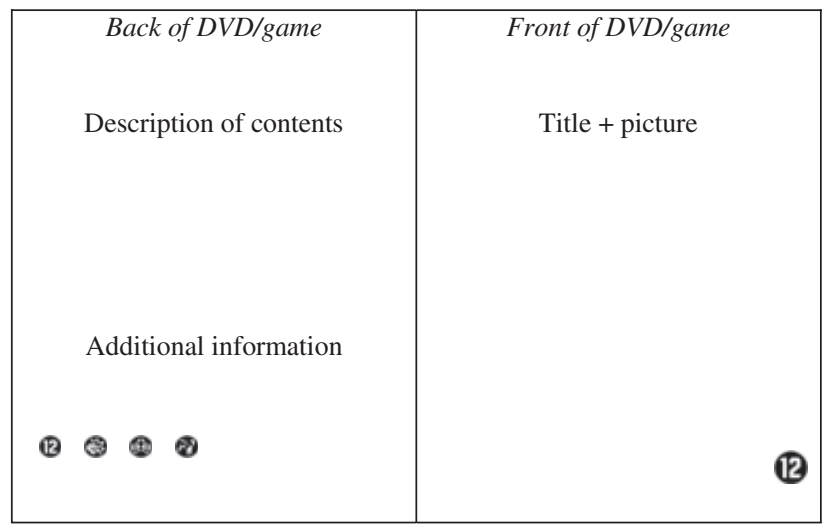

Figure 1 Layout of the experimental material: DVD/game cover with age classification "12 years" and warning labels for violence, sexuality, and abusive language.

\section{Procedure}

The experiment was conducted at several elementary schools and high schools in The Netherlands. The test materials were programmed using Authorware on 10 laptop computers. Participants individually participated in the experiment. To this end, they received a personal code and were assigned to one of the laptops. Based on their personal code, every participant was randomly assigned one condition by the computer program. These conditions were defined by (a) the choice between DVDs and games, (b) one of the four categories of age classification, and (c) the presence or absence of warning pictograms. After a short introduction of the research and a practice screen, the participants were shown 10 DVDs or 10 games in random order. First, the cover appeared on the screen for 10 seconds. Then four screens followed with the four questions concerning the attractiveness of the DVD or game just below the cover. At the end of the session the questions concerning reactance and sensation seeking followed, as well as some background questions. The study was presented to the participants as a study into the preferences of children for DVDs or games. Each session lasted approximately 10 minutes.

\section{Participants}

The participants were students from multiple elementary schools (322 participants, aged 9-11 years) and multiple high schools (335 participants, aged 13-15 years). The two different age categories were chosen because the effects of age and content warning pictograms might be different according to the participants' age (Bushman \& Cantor, 2003). Of the high school participants, 41\% followed lower secondary professional education, 34\% higher general secondary education, and 25\% preuniversity education. No differentiation in educational levels among elementary school participants was possible, as differentiation in educational levels only starts in high school. The proportion of boys to girls was reasonably in balance (313 boys and 344 girls). 


\section{Results}

To map the effects of the age and warning pictograms, the average attractiveness scores were calculated for the six manipulated DVD covers and the six manipulated game covers. In the analysis, these average attractiveness scores formed the dependent variable. Regarding the age classifications, we distinguished three categories: (a) the absence of an age classification, (b) an age classification that indicated that the participant was old enough for the media product, and (c) an age classification indicating that the participant was too young for the media product. We included this variable in our analysis as an independent variable. The other independent variables were the participants' gender, age category, the medium type (DVD or game), and the presence or absence of content warning pictograms. The participants' scores on the reactance and sensation seeking scales were used as covariates in the analysis. Main effects as well as two-way interactions were considered. Based on the average effect size found in samples of children and adolescents (.21, cf. Bushman \& Cantor, 2003), using an $\alpha$ of .05, our post hoc power analysis proved to be satisfactory (.999) (Erdfelder, Faul, \& Buchner; 1996). Even for the smallest effect size reported by Bushman \& Cantor (2003) (.13), the power of our design proved to be sufficient (.854). Table 4 shows the ANCOVA results.

Our most important finding is that the age and content warning pictograms did not make the media products more appealing to the participants. Concerning the age pictograms, no significant differences were found between the three conditions (no age pictogram: $M=6.00$, participant old enough: $M=6.02$; participant too young: $M=6.01)$. Concerning the warning pictograms, there appeared to be a tendency $(p=.058)$, but in the opposite direction: DVDs and games without warning pictograms received, on average, higher scores $(M=6.08)$ than those with

Table 4 ANCOVA Results for the Attractiveness of the Manipulated DVDs and Games

\begin{tabular}{lcrc}
\hline & $d f$ & $F$ & Significance \\
\hline Age pictogram & 2,656 & .330 & .719 \\
Warning pictogram & 1,656 & 3.603 & .058 \\
Reactance & 1,656 & 5.772 & .017 \\
Sensation seeking & 1,656 & 11.483 & .001 \\
DVD or game & 1,656 & 3.882 & .049 \\
Gender & 1,656 & .993 & .319 \\
Age category & 1,656 & .420 & .517 \\
Warning Pictogram $\times$ Age Category & 1,656 & 4.707 & .030 \\
Reactance $\times$ Sensation Seeking & 1,656 & 5.853 & .016 \\
Age Category $\times$ Sensation Seeking & 1,656 & 7.566 & .006 \\
DVD or Game $\times$ Gender & 1,656 & 31.113 & .000 \\
DVD or Game $\times$ Age Category & 1,656 & 14.739 & .000 \\
\hline Note: Ony the significant two-way &
\end{tabular}

Note: Only the significant two-way interactions are included in this table. 
warning pictograms $(M=5.94)$. The DVDs included in our study were considered to be more attractive than the games $(M=6.31$ vs. $M=5.71)$. Preferences for either DVDs or games differed significantly between girls and boys (girls were relatively more positive about DVDs, and boys relatively more positive about games), and between elementary school students and high school students (elementary school students were relatively more positive about games, and high school students relatively more positive about DVDs).

Subsequent analyses focused on the functioning of the age pictograms and content warnings within the two age categories. Elementary school students (9-11 years old) were exposed to DVD or game covers without age pictograms, DVDs or games that were suitable for their age ("all ages"), DVDs or games classified as appropriate for minors slightly above their age ("12 years") and DVDs and games classified as far above their age ("16 years"). No significant differences were found between the four conditions (no age pictogram: $M=6.23$; participant old enough ("all ages,"): $M=6.35$; participant slightly too young ("12 years,"): $M=6.26$; participant far too young ("16 years"): $M=6.30 ; F(3,321)=.125, p=.945)$. The content warning pictograms appeared to make the media products significantly less appealing to the elementary school participants: present, $M=6.12$; absent, $M=6.45$; $F(1,321)=5.583, p<.05$.

High school students (13-15 years old) were exposed to DVD or game covers without age pictograms, DVDs or games that were suitable for their age ("all ages" and "12 years"), and DVDs or games classified as above their age ("16 years"). In this analysis, we also included the educational level of the participants. Again, media products' age classifications had no significant effect on their attractiveness (no age pictogram: $M=5.66$; participant old enough ("all ages"): $M=5.31$; participant old enough ("12 years"): $M=5.77$; participant too young ("16 years"): $M=5.60$; $F(3,333)=2.248, p=.083)$. The content warning pictograms did not significantly affect the attractiveness of media products either (present: $M=5.61$; absent: $M=5.56 ; F(1,333)=.127, p=.722)$. No significant interaction effects were found between participants' educational level and age pictograms, $F(6,333)=.757$, $p=.605$ or content warning pictograms, $F(2,333)=.348, p=.706$.

The literature on the forbidden fruit effect suggests that the occurrence of this effect is related to adolescents' reactance and sensation seeking scores. Our final analysis therefore focused on a subset of participants with relatively high scores on both variables. Using a median split $(M d n=2.5$ on reactance, and $M d n=3.1$ on sensation seeking), we selected only those participants who had stronger tendencies toward reactance and sensation seeking $(n=270)$, and repeated our first analysis (except for the covariates). Even within this group of participants, no effects were found of age pictograms (no classification, $M=6.16$; participant old enough, $M=6.08$; participant too young, $M=6.15 ; F(2,269)=.260, p=.771)$ or content warning pictograms (present: $M=6.09$; absent: $M=6.17 ; F(1,269)=.047$, $p=.829)$. 


\section{Discussion}

Media rating systems are designed to provide information concerning the content of media products and, by doing so, to serve as a potentially important tool for restricting minors' access and exposure to harmful media. Several stakeholder groups may be identified: parents or caregivers, retailers, and minors. Parents or caregivers may use these systems to make informed decisions regarding the exposure of their children to media products. Research indeed shows that parents highly appreciate these systems and find them useful in assessing to what extent media products may be suitable for their children (Nikken, Jansz, \& Schouwstra, 2007). Media ratings also help retailers to comply with national laws or regulations. The systems function as a means to determine which media products can responsibly and legally be shown, sold, or rented to younger audiences. Research shows that there is still much to be gained in this respect: Retailers of media products generally do not comply with age restrictions when selling or renting media products to minors (Gosselt, Van Hoof, \& De Jong, in press). Still, the existence of a broadly accepted media rating system can be considered to be a precondition for retailers to be able to act responsibly when showing, selling, or renting media products to minors.

The third stakeholder group is the minors themselves. Media rating systems might help minors decide whether or not they want to watch a certain movie or program or play a certain game. In general, however, it seems to be too optimistic to assume that minors will regulate their own media consumption using age classifications. Earlier studies have reported undesirable side effects of media ratings on minors: Age classifications and warning pictograms may make potentially harmful media products more appealing for children and adolescents. A possible flaw in these earlier studies is the artificial nature of the stimulus materials used. Compared to those earlier studies, we used experimental materials with richer product information, which is more realistic in the case of media products like DVDs and games, to verify the existence of a forbidden fruit effect and found no evidence for such an effect. In the more realistic setting of our experiment, age and content warning pictograms did not appear to make potentially harmful media products more attractive to children and adolescents. This would mean that the systems can fulfill their functions for the other two stakeholder groups without undesirable side effects on minors.

The results of earlier research do not suggest that national contexts play an important role. In all recent studies using a similar design, a forbidden fruit effect was found. This also applies to the studies conducted in The Netherlands and the U.K. The results of our study largely contradict those of earlier studies, including the study by Nije Bijvank et al. (2008), which was conducted in the same national context and with the same classification systems (Kijkwijzer and PEGI). This may be attributed to the differences in the experimental materials used. In our study, participants were exposed to richer visual and verbal stimuli about the media products themselves (a normal cover of the DVD or game), with less emphasis on the classifications (placed in normal size and position on the covers). The materials that we used 
correspond to the normal way of presenting media ratings in The Netherlands. It is conceivable that the forbidden fruit effect found in earlier studies is caused by the unfavorable combination of poor information about the media products and a strong emphasis on the classifications.

The results of our study are inconsistent with both reactance theory and commodity theory. According to these theories, restricting a person's freedom of choice will motivate this person to try to restore the freedom. The underlying psychological mechanisms of the forbidden fruit hypothesis may still be valid, but the actual placement of the pictograms on DVDs and games may be too insignificant to trigger such reactions in real life. Apparently the respondents did not experience any loss of freedom, nor did they perceive the DVDs and games as unavailable commodities because of the ratings on the covers.

This corresponds to two possible explanations, which call for follow-up research. First, the effects that the pictograms could have had on minors may have been counteracted by the richer (visual and verbal) information on the DVD and game covers. Participants may have seen and processed the pictograms, but the information conveyed in these images did not add much to the much richer information on the rest of the cover. It would therefore be interesting to further explore the balance between the richness of media product information and the emphasis on the pictograms in forbidden fruit experiments. Second, participants may not have noticed the pictograms on the DVD and game covers. It would therefore be interesting to combine a similar experimental design with eye-tracking data, which provides additional information about the extent to which participants notice and pay attention to the pictograms. Some of our results, however, support the assumption that the children and adolescents in our study at least paid some attention to the pictograms. After all, the elementary school students' appreciation of DVDs and games was negatively influenced by the presence of warning pictograms.

It is important to note that our study, like all other experimental studies on the forbidden fruit effect, has some limitations that must be taken into account. First, our study is solely based on individual assessments, whereas it is conceivable that the age classifications and content warning pictograms also play a role in the way children and adolescents talk with each other about DVDs and games. Second, even though our stimulus materials were realistic, participants may have looked at the covers differently because they were not presented in their natural context (a store, library, or video store), but in an artificial test setting using a computer presentation. Further, our study specifically focused on covers of DVDs and games. The balance between media product information and ratings may be different in the case of for instance a television program listing. Our findings therefore do not necessarily apply to the effects of media ratings in television guides or other outlets. It would be interesting to devote future research to that particular area. Third, only two media rating systems and one national context were involved in our study. The nature, size, and placement of the pictograms, the extent to which media rating systems are disseminated and adopted in society, the perceived strictness of the media rating 
systems, and the extent to which minors have experience with potentially harmful media may differ between nations and may affect the results of an experiment such as this one. Fourth, our study is restricted to the effects of a particular combination of warning pictograms (violence, sexuality, and abusive language). Future research could focus on the effects of individual pictograms or different combinations. Lastly, as our pretest revealed, the attractiveness of the DVDs and games used in our study was moderate. It would be interesting to vary the attractiveness of medium products and then investigate the interaction between the attractiveness of the product and the occurrence of a forbidden fruit effect.

In all, the study reported in this article leads to the conclusion that the pictograms of media rating systems do not necessarily make media products more attractive to children and adolescents. The findings of our study call for new directions in the research into the forbidden fruit effect: Rather than investigating the general mechanism of the forbidden fruit effect, which has been confirmed by many earlier studies, future research should address the conditions under which the forbidden fruit effect is likely to occur.

\section{References}

Anderson, C. A., \& Bushman, B. J. (2001). Effects of violent video games on aggressive behavior, aggressive cognition, aggressive affect, physiological arousal, and prosocial behavior. A meta-analytic review of the scientific literature. Psychological Science, 12, 353-359.

Austin, B. A. (1980). The influence of the MPAA's film-rating system on motion picture attendance: A pilot study. Journal of Psychology, 106, 91-99.

Bahk, C. M. (1998). Descriptions of sexual content and ratings of movie preference. Psychological Reports, 82, 367-370.

Brehm, J. W. (1972). Responses to loss of freedom: A theory of psychological reactance. Morristown, NJ: General Learning Press.

Brehm, S. S., \& Brehm, J. W. (1981). Psychological reactance. New York, NY: Wiley.

Buchman, D. D., \& Funk, J. B. (1996). Video and computer games in the '90s: Children's time commitment and game preference. Children Today, 24, 12-16.

Bushman, B. J. (2006). Effects of warning and information pictograms on attraction to television violence in viewers of different ages. Journal of Applied Social Psychology, 36, 2073-2078.

Bushman, B. J., \& Anderson, C. A. (2001). Media violence and the American public: Scientific facts versus media misinformation. American Psychologist, 56, 477-489.

Bushman, B. J., \& Cantor, J. (2003). Media ratings for violence and sex: Implications for policymakers and parents. American Psychologist, 58, 130-141.

Bushman, B. J., \& Huesmann, L. R. (2001). Effects of televised violence on aggression. In D. G. Singer, \& J. L. Singer (Eds.), Handbook of children and the media (pp. 223-254). Thousand Oaks, CA: Sage.

Bushman, B. J., \& Stack, A. D. (1996). Forbidden fruit versus tainted fruit: Effects of warning pictograms on attraction to television violence. Journal of Experimental Psychology: Applied, 2, 207-226. 
Cantor, J., \& Harrison, K. (1997). Ratings and advisories for television programming. National television violence study (Vol. 1, pp. 361-410). Thousand Oaks, CA: Sage.

Cantor, J., Harrison, K., \& Nathanson, A. (1998). Ratings and advisories for television programming. National television violence study (Vol. 2, pp. 267-322). Thousand Oaks, CA: Sage.

Christenson, P. (1992). The effects of parental advisory labels on adolescent music preferences. Journal of Communication, 42, 106-113.

Earles, K. A., Alexander, R., Johnson, M., Liverpool, J., \& McGhee, M. (2002). Media influences on children and adolescents: Violence and sex. Journal of the National Medical Association, 94, 797-801.

Erdfelder, E., Faul, F., \& Buchner, A. (1996). GPOWER: A general power analysis program. Behavior Research Methods, Instruments \& Computers, 28, 1-11.

Ferguson, C. J., \& Kilburn, J. (2010). Much ado about nothing: The misestimation and overinterpretation of violent video game effects in Eastern and Western nations: Comment on Anderson et al. (2010). Psychological Bulletin, 136, 174-178.

Gentile, D. A., Humphrey, J., \& Walsh, D. A. (2005). Media ratings for movies, music, video games, and television: A review of the research and recommendations for improvements. Adolescent Medicine Clinics, 16, 427-446.

Gosselt, J. F., Van Hoof, J. J., \& De Jong, M. D. T. (in press). Media rating systems: Do they work? Shop floor compliance with age restrictions in the Netherlands. Mass Communication and Society.

Herman, G., \& Leyens, J. P. (1977). Rating films on TV. Journal of Communication, 27, $48-53$.

Hogben, M. (1998). Factors moderating the effect of television aggression on viewer behavior. Communication Research, 25, 220-247.

Hong, S. M., \& Page, S. (1989). A psychological reactance scale: Development, factor structure and reliability. Psychological Reports, 64, 1323-1326.

Hoyle, R. H., Stephenson, M. T., Palmgreen, P., Lorch E. P., \& Donohew R. L.(2002). Reliability and validity of a brief measure of sensation seeking. Personality and Individual Differences, 32, 401-414.

Huesmann, L. R. (2007). The impact of electronic media violence: Scientific theory and research. Journal of Adolescent Health, 41, 6-13.

Ingold, C. H. (1999). Television audiences' responses to "mature subject matter" advisories. Psychological Reports, 85, 243-245.

Konijn, E. A., Nije Bijvank, M., \& Bushman, B. J. (2007). I wish I were a warrior: The role of wishful identification in the effects of violent video games on aggression in adolescent boys. Developmental Psychology, 43, 1039-1043.

NICAM (2006). Jaarverslag (Annual Report 2006). Hilversum, The Netherlands: NICAM.

Nielsen Games (2008). Video Gamers in Europe. ISFE Consumer Research-April 2008.

Nije Bijvank, M., Konijn, E. A., Bushman, B. J., \& Roelofsma, P. H. M. P. (2008). Age and violent content labels make video games forbidden fruits for youth. Pediatrics, 123, 870-876.

Nikken, P., Jansz, J., \& Schouwstra, S. (2007). Parent's interest in videogame ratings and content descriptors in relation to game mediation. European Journal of Communication, 22, 315-336.

Nikken, P., \& Jansz, J. (2007). Playing restricted videogames: Relations with game ratings and parental mediation. Journal of Child and Media, 1, 227-243. 
Paik, H., \& Comstock, G. (1994). The effects of television violence on antisocial behavior: A meta-analysis. Communication Research, 21, 516-546.

Savage, J., \& Yancey, C. (2008). The effects of media violence exposure on criminal aggression: A meta-analysis. Criminal Justice and Behavior, 35, 1123-1136.

Sherry, J. (2001). The effects of violent video games on aggression: A meta-analysis. Human Communication Research, 27, 409-431.

Sherry, J. (2007). Violent video games and aggression: Why can't we find links?. In R. Preiss, B. Gayle, N. Burrell, M. Allen, \& J. Bryant (Eds.), Mass media effects research: Advances through meta-analysis (pp. 231-248). Mahwah, NJ: Erlbaum.

Simmons, B. (1992). The effect of censorship on attitudes toward popular music. Popular Music and Society, 16, 61-67.

Sneegas, J. E., \& Plank, T. A. (1998). Gender differences in preadolescent reactance to age-categorized television advisory labels. Journal of Broadcasting and Electronic Media, 42, 423-434.

Valkenburg, P. M., Beentjes, J. W. J., \& Nikken, P. \& Tan E. (2002). Kijkwijzer: The Dutch rating system for audiovisual productions. Communications - The European Journal of Communication Research, 27, 79-102.

Van Grinsven, M. (2009). Kijkwijzer en PEGI: Iconen van de mediaclassificatie. Evaluatie van de pictogrammen op de classificatielabels voor audiovisuele media in Nederland. Master's thesis, University of Twente, Enschede.

Wurtzel, A., \& Surlin, S. (1978). Viewer attitudes toward television advisory warnings. Journal of Broadcasting, 22, 19-31. 